provement of some patients after the settlement of damage claims, but this seemed to be due to the relief from worry which the conclusion of the suit afforded; but it would be presumption to affirm that such cases were entirely cured until years had elapsed and unprejudiced opinion been engaged. This "quick cure by settlement" savored too much of the unscientific assertion of Herbert Page, who was the most ordinary special pleader for railways.

While both Dr. Gapen and Dr. Judd had been opposed to Dr. Clevenger in recent suits against corporations, and seemed to look at the matter from one standpoint, the latter had frequently been called as expert for either side, and sometimes for both sides at the same time.

The statement that there were no vaso-motor centres in the spinal cord, and hence the symptoms were cerebral, was rather surprising, when the sympathetic system is so intimately united to the spinal all the way down the cord length, and such ordinary matters as constipation and hæmorrhoids producing brain troubles show that such "vaso-motor" difficulty as emotionalism need not have its origin necessarily in the head.

The intimation that subjective symptoms were always false, when made the basis of claims against railways, is on its face absurd. Physicians have to judge from the consistency of symptoms whether they were real or not.

Contrary to Dr. Gapen's findings, Dr. Clevenger had devoted all his spare time for three months in analyzing Erichsen's cases, and found an abundance of objective signs in all. But it depends upon what is meant by "objective." To the uneducated the galvanometer and electrical indications convey no meaning. Paralysis and insanity of the gravest kinds would present nothing "objective" to the biased witness. There are cases in which no honest opinion can be reached, and in such it is best to allow the mind to remain a " scientific blank," as Huxley advises. Only the untrained imagine they must have a positive opinion upon everything under the sun. Somettimes a little waiting will determine matters.

A case examined a year ago presented nothing ibut purely subjective symptoms, and to-day there is atrophy of an arm. In another instance a laborer fell partly into a coal hole, with one leg in and the other out, and after a year is unable to do any work, but there was such an utter absence of anything in the way of electrical or other findings, and so many of the ordinary symptoms of Erichsen's disease were missing, that Dr. Clevenger told the lawyers that everything depended apon the credibility of the witness, and he preferred having nothing to do with the case as it stood at present.

We find many instances, in and out of the books, of fatal issues among patients accused of malingering. We occasionally find a conscien- tious railway surgeon who acknowledges that railway accidents do not always improve health, and that a few dollars' settlement will not resurrect the dead.

A NEW METHOD OF LARYNGEAL AND BRONCHIAL MEDICATION BY MEANS

OF A SPRAY AND TUBE DURING

THE AC'T OF DEEP INSPIRATION.

Read in the Section of Laryngology and Otology at the Forty-first Annual Meeting of the American Medical Association, Nashville, Tenn., May, 1890.

BY J. MOUN'T BLEYER, M.D., OF NEW YORK.

I bring before you a novel method and use of the ordinary cold spray. By the extra aid of a hard rubber tube six inches in length and threequarters of an inch in diameter on both sides of its openings, through which a cold spray with tip pointing downwards is passed and held in the mouth between the lips which are clasped over the tube. With this tube, spray, and position of the lips and deep inspirations any desired medicated fluid amounting from a half to one ounce may be forcibly inhaled during the act of ten deep inspirations, and thus reach the deeper portions of the respiratory tract, without coughing, gagging, or immediately expectorating the fluid thus inhaled. The time occupied for re-expectorating the fluid medicament thus inhaled varies in different individuals. Some begin lightly within from five to ten minutes after the inhalation, others again half to three-quarters of an hour later. The sputa which is expectorated for several hours after contains a certain amount of the medicated inhalent used, showing thereby that the desired medicament used remains in contact with the diseased parts long enough to have its therapeutic effect.

The Method of Making an Application.-The patient is placed in an upright position, or, better, standing. The collar or tight dress about the neck is removed so that nothing interferes with taking deep and slow inspirations. The position of the head is an important point to be observed. It must be inclined backwards during the act of each inspiration so as to destroy as much as possible the rectangular curve that the windpipe makes with the oral cavity. The patient before being made to use these two instruments, must be shown how to take deep inspirations and slow expirations without exerting himself. He must also be taught how to hold in the breath for a few seconds after each inspiration. Those are some of the cardinal points to be looked after in order to get the results from each inspiration. These points are easily acquired by patients. When once understood how to make use 
of such inspiratory and expiratory powers, without the spray and tube, then begin the same method over again; with this exception that the instrument (spray and tube) are now used for practice, as if the patient was taking an inhalation. Place the tube half its length into the mouth; the lips are clasped over it. The spray is placed into the opening of the hard rubber tube into which the spraying tube is inserted so that its inner end protrudes not more than one-quarter of an inch. This point regarding the size and position of the tube is very important. The best motor power for the propulsion of the spray, to my mind, is compressed air. The pressure need not exceed $60 \mathrm{lbs}$. This will suffice for any application.

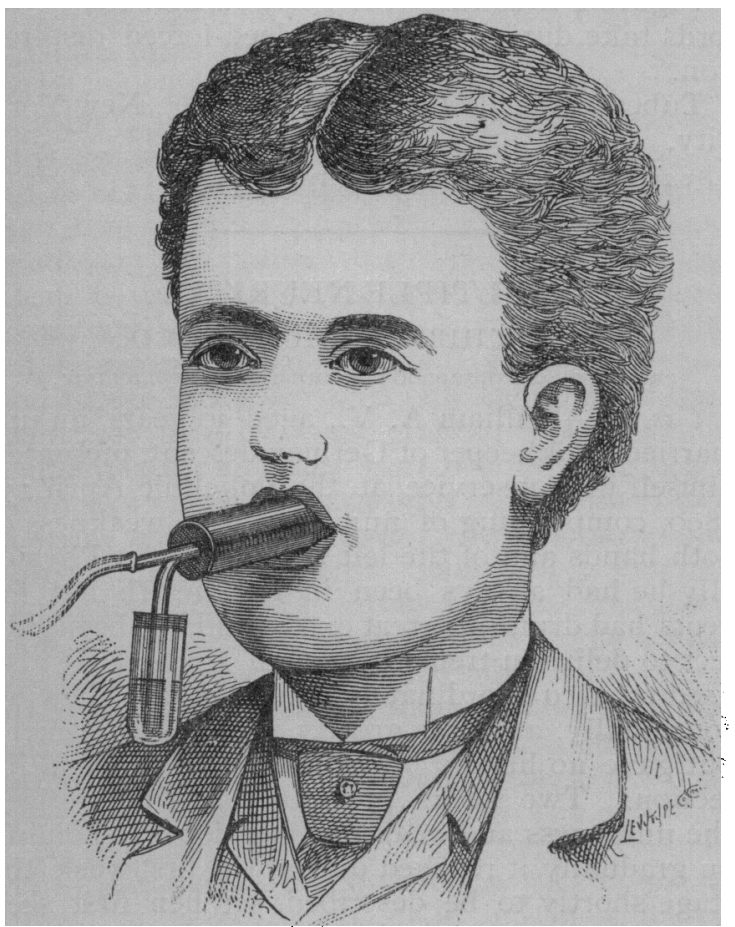

FIGURE $x$.

It will be found during the act of deep-forced inspiration that the vocal cords separate and, still further, on inspiration they will separate to their entire extent. In the subsequent expiration they will again approach each other. During inspiration the vocal cords form a wide and almost pentagonal opening, and under favorable circumstances one can on examination then see the bifurcation of the trachea; as seen in the accompanying drawing.

The epiglottis stands nearly erect, if not, through its anatomical formation, is curled upon itself or may assume another shape. These physiological facts are known to every one who practices with a laryngoscope.

The tube serves as an adjunct to the propulsion of the specified inhalent. The tube, and the act of deep inspiration, also diverts the attention of the inhaler, and thereby calling into action another set of muscles favoring the passage of the inhalent. During the act of deep inspiration the tongue lays flat in the mouth, and as described before, the vocal cords and epiglottis are now in a position to permit the passage of the medicant, and assisted in reaching the desired spot by the propelling force of compressed air.

I have made numerous experiments with this method of application upon the dog and rabbit before using it upon my patients, the details of which are beyond the scope of this paper. Never-

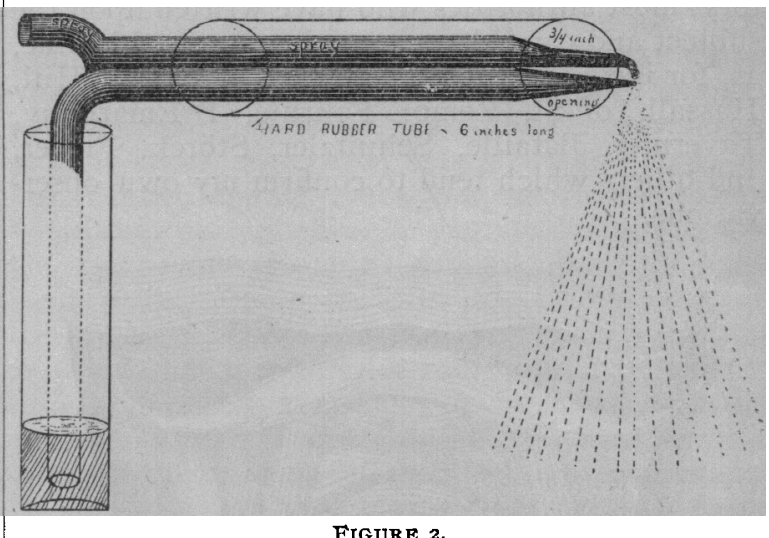

theless, I will give a short description of one of these experiments in order to show the effectiveness of this method in the application of medicaments in a fluid state to the deeper portion of the respiratory tract.

A healthy dog weighing fifty pounds was placed upon a table. The mouth was opened and the rubber tube inserted to its proper length. The mouth was then fastened over the tube by straps made for the purpose. The tube being open the respiration was thus carried on undisturbed. The spray was then attached and the animal made to inhalate. The substance used was a strong solution of the extract of rhatany, the quantity sprayed being half an ounce. This almost immediately brought out a bright.

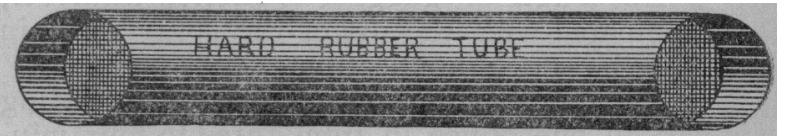

FIGURE 3.

redness of the larynx, trachea, and of the bronchi, which entirely disappeared after the discontinuance of the spray in about two hours from those parts under examination.

The sputa, however, continued to be red some five hours longer; at this point the animal was killed and a post-mortem examination was made. Quantities of the fluid inhaled were found depos- 
ited throughout the trachea and smaller bronchi. Other experiments made with the same end in view gave similar results.

It is a well known fact that finely divided sub. stances do penetrate into the air cells, as in the case of colliers, grinders and others who are constantly inhaling pulverized particles and matter while engaged in their occupations. On the other hand it is extremely doubtful if any of the medicaments used in any of the numerous inhalers at present in vogue ever reach the walls of the ultimate lung alveoli. The conditions under which and the extent to which sprays and vapors enter the lungs are to a certain extent satisfactory, most authorities who have written upon the subject and carried on experiments in this line, as, for instance, those made by Dr. Arthur Hill, Hassall, of St. Remo; Fournie, D'Emarguay, Tavernier, Bataille, Schnitzler, Störck, Fieber, and others which tend to confirm my own observations.

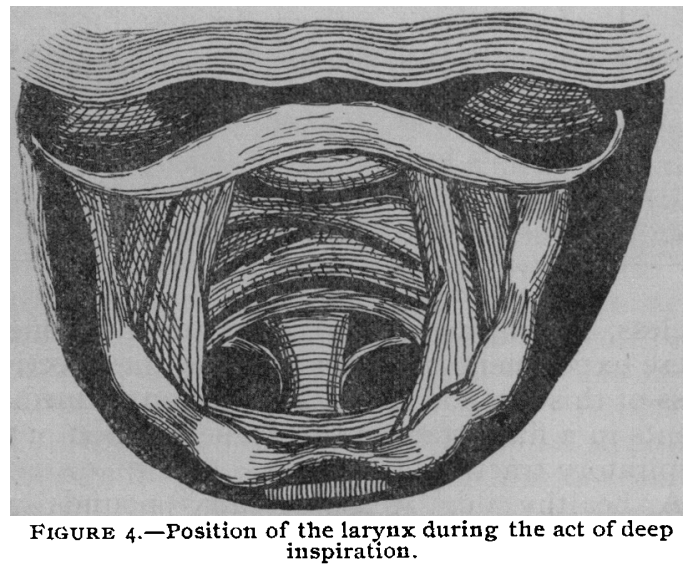

The advantages of the method I have described are as follows:

I. Cheapness of the instrument, which is simply a hard rubber tube.

2. The advantage of the continued effects of the remedy as the time between each application lasting five hours, until another is necessary, and then the patient can satisfactorily make it himself and thus keep up the remedial effects.

3. No cough or gagging is excited whatever, as compared with the use of the spray alone in making laryngeal application.

4. The quantity of fluid inhaled at each sitting is half to one ounce in from three to four minutes' time.

5. When applied to the larynx, trachea and bronchi no spasmodic contractions arise during its use whatsoever.

6. Irritating medicaments in solution can be thus applied without exciting much cough. I often use nitrate of silver, thirty grains to the ounce, iodine, tannic acid, peroxide of hydrogen of full strength without any trouble or bad effects.
My results in the treatment of (Störck's disease) or ozæna of the trachea, acute and chronic bronchitis, laryngitis, tracheitis, phthisis, etc., have given me such satisfaction that I bring this method before your notice.

For the want of more time I was compelled to shorten my paper.

Several drawings accompany this paper. Figure I demonstrates the exact position of the lips around the tube during the act of deep inspiration.

Figure 2 shows a Sass' glass downward pointing spray passed through the hard rubber tube, the spray points looking out at the opposite opening a quarter of an inch.

Figure 3 shows the tube.

Figure 4 illustrates the position that the voca cords take during the act of deed-forced inspiration.

Tubes are made by Tiemann \& Co., New York City.

83 2nd avenue, New York City.

\section{MULTIPLE NEURITIS.}

BY ARCHIBALD CHURCH, M.D.,

PROFESSOR OF NEUROLOGY IN THE CHICAGO POLICLINIC.

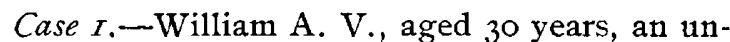
married bookkeeper of German descent, presented himself in my service at the Policlinic April I7, I89o, complaining of numbness and weakness of both hands and of the left leg and foot. Physically he had always been in fair health but for years had drunk to great excess and had been subject to delirium tremens several times. He also used tobacco inordinately, smoking and chewing continually, and was greatly addicted to venery but gave no history or indication of venereal infection. Two weeks previously he first noticed the numbness and weakness mentioned. Coming on gradually it reached during the first week the stage shortly to be described. When first seen the patient was tremulous, uncertain in speech, with dilated pupils and the general manifestations of a prolonged debauch. At this particular time the critical illness of an uncle was making additional demands upon his strength, as he was compelled to watch with him day and night and had lost much sleep. He presented an irritable pulse of one hundred beats, a normal temperature, a fair digestion, an active bowel and was moderately well nourished. His attitude when standing was natural, but he walked with a decided limp, dragging the toe of the left foot, which was advanced and brought to the ground in an uncertain, dangling, flail-like manner, the muscles failing to properly control the ankle-joint. The anterior tibial group of muscles were found completely paralyzed and the other leg muscles weakened. On the anterior surface of the leg there 